\title{
Numerical study of the transparent cover effects with miscellaneous shapes on the parabolic trough solar collector performance
}

\author{
Behnam Pourkafi $^{1 *}$, Behrooz M. Ziapour ${ }^{1}$, Ali Reza Miroliaei ${ }^{2}$ \\ ${ }^{1}$ Department of Mechanical Engineering, University of Mohaghegh Ardabili, Ardabil, Iran \\ ${ }^{2}$ Department of Chemical Engineering, University of Mohaghegh Ardabili, Ardabil, Iran \\ E-mail: "behnampourkafi@gmail.com
}

Received 4 August 2019, Revised 25 November 2019, Accepted 7 December 2019

\begin{abstract}
Optimization of energy production equipment due to significant production cost of each unit of energy is one of the most significant factors for economic development and countries progress. The aim of this work is to improve the efficiency of the parabolic trough collector (PTC) by reducing the heat losses from it. Therefore, it was utilized a PTC with a receiver tube in the focal center of the concentrator that was applied a phase change material (PCM) inside it to store better energy. In the present work, by adding a new section called transparent cover to envelope the PTC, waste of thermal energy from the receiver tube was prevented. The numerical solutions were performed for both summer and winter days. By using of existing formulas, energy and exergy efficiency of the PTC system with different geometrical shapes and heights were obtained and their performance were compared. The results showed that by reducing the height of the covers (i.e. reduction of the space), energy and exergy efficiencies were increased and by providing the triangular cover shape, the system performed better than two others elliptical and rectangular shapes.
\end{abstract}

\section{Keywords: Efficiency; optimization; parabolic trough collector; phase change material; solar energy.}

\section{Introduction}

Increasing demand for energy, reducing the amount of fossil fuels, and most importantly, endangering the life of living creatures through environmental pollution has increased the trend towards renewable energy production and consumption [1] .Solar energy is one of the most massive, affordable and cheapest renewable energy in the world [2].

Solar collectors are devices that convert solar radiation into thermal energy. Energy is transferred from a distant source (sun) to a heat transfer fluid (HTF) in the collector. The most common solar collectors are flat plate collectors that are used for low temperature applications up to $100^{\circ} \mathrm{C}$ and domestic hot water production [3]. Evacuated tube collectors cover the temperature above $200^{\circ} \mathrm{C}$ [4]; and concentrating solar collectors are the only possible solution to reach the highest temperature ranging from 200 to higher temperatures [5]. Basically, there are the several technologies for concentrating collectors as: Linear Fresnel collectors, parabolic dish collectors, parabolic trough collectors, solar towers and compound parabolic collectors which parabolic trough collectors (PTC) are the most extensive between them with covering $90 \%$ of the entire concentrating solar power (CSP) systems [6].

Numerous studies have been carried out on concentrating solar collectors to optimize their design and operation. Providing a general method for the development of geometric parameters of the concentrator surface and receiver tube [7], offering a new solar tracking system to improve the efficiency of the concentrator solar collector [8] Design and manufacture of a new fiberglass reinforced parabola trough for PTC, which its thermal performance is determined, based on ASHRAE STANDARD 93 (1986) [9].
In addition, thermal analysis of the solar parabolic trough collector based on nanofluids has been studied by researches [10].

In another work, Paetzold et al. [11] studied the effects of the wind on a PTC. In a fixed aperture, they investigated the variations of the focal length of the parabola in order to minimize the effects of the wind on parabolic trough collector and to optimize the shape and design of the PTC.

One of the most widely methods in radiation is the Monte Carlo Ray Tracing (MCRT) method. This is one of the most efficient methods for radiation issues in PTCs. SerranoAguilera et al. [12] used this method to analyze the efficiency of the parabolic trough concentrator in proportion to its shape. In another work, Wang et al. [13] analyzed the effects of glass cover on the receiver tube using the Monte Carlo Ray Tracing method. They concluded that minimizing the distribution of heat flux gradient on the surface of the receiver tube could reduce the thermal stresses on the receiver tube and found that the glass cover with the elliptic cross-section in comparison to the circular cross-section could effectively reduce the heat flux gradient.

Furthermore, a few of studies have focused on experimental set-ups. In an experimental study, Zoe et al. [14] introduced a small-sized PTC to heat water in cold regions. In this research, an experiential platform was fabricated and developed then comprehensive experiments was carried out to evaluate the thermal performance of the PTC. In another experimental study, Potenza et al. [15] examined a new parabolic trough collector with a transparent receiver tube that operates with a gas-based nanofluid as a working fluid.

Due to the advancement of computer technology and its low cost, compared with experimental equipment, numerous 
numerical studies have been done by researchers for several models of PTCs. By investigating the works of these researchers, it is observed that numerical methods were used for both of the radiation region and outer region of the receiver tube and for the working fluids inside the tube.

Hachicha et al. [16] presented a precise numerical model based on a large eddy simulation (LES) to peruse the fluid flow and heat transfer in a PTC and its receiver tube. Their study provided a quantitative assessment of the pressure, velocity and temperature values around an isolated PTC and its receiver tube. Numerical results validated with experimental data, which was well-agreement, though there were some discrepancies due to unsteady behavior of flow. To clarify the variations in the aerodynamic coefficients, the instantaneous flow around the parabola was studied at various pitch angles and they concluded that the horizontal position $\theta=90$ is the most appropriate position for the PTC system to work.

In another numerical study, a detailed model based on the energy balance at the component level in order to investigate the thermal performance of a PTC in transient climatic conditions was developed and validated by Lamrani et al. [17]. They studied the effects of the important parameters such as the mass flow rate of HTF, receiver tube length and fluid type on the thermal performance of a PTC. They concluded that maximum efficiency of the PTC system could reach around $76 \%$ during the summer. In addition, it was shown that the outlet temperature of HTF is more affected by the length of the receiver tube, and using synthetic oil as a working fluid is more appropriate than water.

The main problem with the operation of parabolic trough solar collectors is receiving and transmitting thermal energy with the least losses. To determine the optimized collector performance conditions, exergy analysis besides energy analysis can be a useful way to investigate the efficiency of the parabolic trough solar collectors [18]. Bejan et al. [19] used the second law of thermodynamics for exergy analysis of a solar collector system under variable time conditions. Allouhi et al. [20] proposed a detailed mathematical model to study the energy and exergy performance of a PTC with various nanoparticles suspended in the working fluid at high and moderate temperature. They concluded that improvement of the exergy performance is more important than energy performance, and by providing optimal conditions, the PTC system can achieve peak energy and exergy efficiency.

In an experimental study, Chafie et al. [21] evaluated the thermal performance of a receiver tube of a PTC from two perspectives of energy and exergy. A parabolic trough collector in the laboratory environment was designed and fabricated to analyze energy and exergy performance. Throughout this study, the exergy transferred to the HTF, the useful energy gain and the energy and exergy efficiency were measured. The measured results showed that the thermal performance is strongly influenced by climate conditions. Also, energy and exergy efficiency would be higher under clear sky than the cloud sky.

Moreover, Mwesigye et al. [22] carried out a numerical study on the thermal and thermodynamic performance of a PTC using single-walled carbon nanotubes (SWCNTs) in Therminol®VP-1 nanofluid. They intended to show the effect of high thermal conductivity SWCNTs in the used HTF on the performance indicators of a PTC system. Also, in this study, energy and exergy efficiency of the system for various volume fractions of $0.25,0.5,1,2$ and $2.5 \%$ and the inlet temperature range from $400 \mathrm{~K}$ to $600 \mathrm{~K}$ have been presented

Although, in the past years parabolic trough solar collectors were used only for high temperature applications, especially for power generation or melting, but in recent years these systems have been used for thermal applications in low to high temperatures. This application became important when phase change materials (PCM) were used as energy storage [23]. In the present work, we used a PTC with a receiver tube. To save and better using energy, a defined volume of PCM was applied inside the receiver tube. By adding a new section named transparent cover to coat the PTC system, we prevented the convection heat losses to the surroundings. An innovative work in this paper is to determine the geometry shape of the transparent cover in order to optimize the efficiency of the PTC. To achieve this aim, we resorted to the numerical method and with computational fluid dynamic (CFD) tools, we have numerically analyzed the enclosure. Then, using the first and second law of thermodynamics, the energetic and exergetic performance of the PTC system with various geometric covers have been summarized and presented for a summer and a winter day.

\section{Research methodology \\ 2.1 Physical model}

PTC systems consists of two main components as the parabolic trough concentrator and the receiver tube. The parabolic trough concentrator reflects the solar radiation to the receiver tube that is positioned along the concentrator focal line. The absorbed heat by the receiver tube is transferred to the HTF in it and this thermal energy is extracted for the required applications [24]. A schematic diagram of the cross-section of a PTC and some of its significant parameters, such as aperture width $\left(a_{c}\right)$, focal length (f), and rim angle $(\varphi)$, are shown in Figure 1 [25].

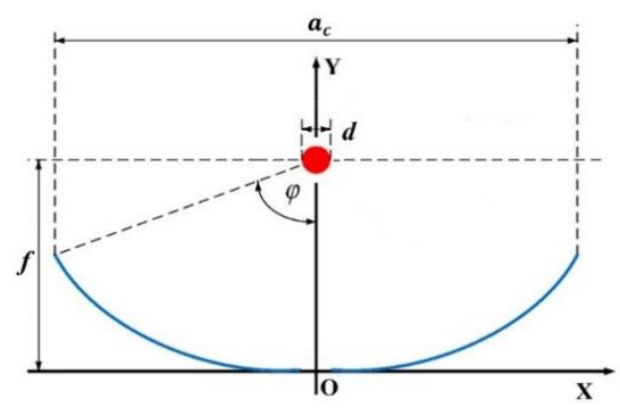

Figure 1. Cross-section of the PTC

Figure 2 also shows the cross section of the three geometric models that have been studied in the present work. In the focal axis of the concentrator, receiver tube with determined diameter is placed and phase change material (PCM) is applied inside it. The diameter of the receiver tube and the volume of phase change material is determined by optimizing the tube dimension versus the PCM volume. The space, above the PTC system is enveloped with a shaped glass cover, which reduces the convection heat losses to the outside.

To determine the optimal diameter of the receiver tube in comparison to the volume of the PCM inside the tube, the energy balance between the entered energy to the receiver tube and the absorbed energy by the water and the paraffin wax as PCM is applied as follows [26]. 
$\left(0.5 G \times A_{\text {in,pipe }}\right)=\rho_{w} V_{w} C_{P_{w}}\left(T_{\text {melt }}-T_{i}\right)+\rho_{p a} V_{p a} C_{P_{p a}}\left(T_{\text {melt }}-\right.$ $\left.T_{i}\right)+\rho_{p a} V_{p a} h_{L_{p a}}$

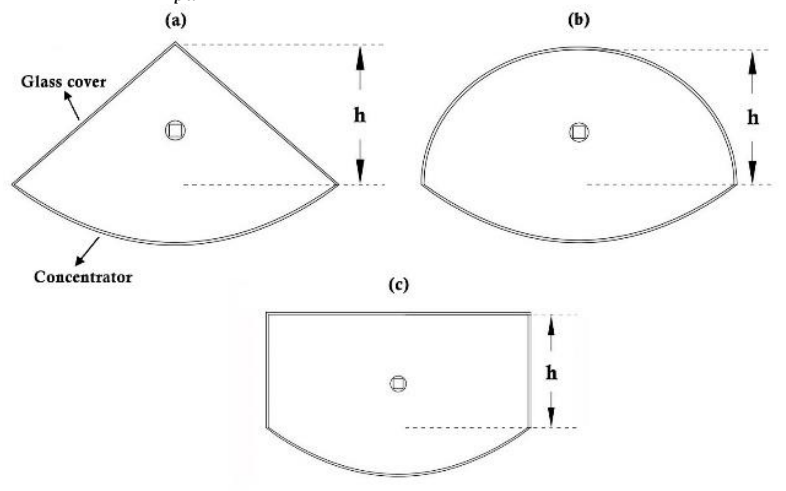

Figure 2. Schematic diagram of PTC system with three shaped glass cover: (a) triangular GC, (b) elliptic GC, and (c) rectangular $G C$.

Left side of equation (1) represents the entered energy to the receiver tube as a function of 50 percent of total solar radiation in a summer day $(G)$ multiplied in the surface area of receiver tube dealt with proportional area of the parabolic trough concentrator $\left(A_{\text {in,pipe }}\right)$, and the right side of it is used for the storage energy inside the receiver tube, where $\rho_{w}, V_{w}, C_{P_{w}}$ refers to density, volume and specific heat capacity of water and $\rho_{p a}, V_{p a}, C_{P_{p a}}$ are density, volume and specific heat capacity for the paraffin wax inside the tube. $T_{\text {melt }}, T_{i}$, respectively, are the melting temperature of paraffin wax and ambient temperature, as well as, $h_{L_{p a}}$ is the paraffin melting latent heat.

To simplify the calculations, the PCM volume is considered as a cubic shape with a square cross-sectional length a, inside the receiver tube as shown in Figure 3.

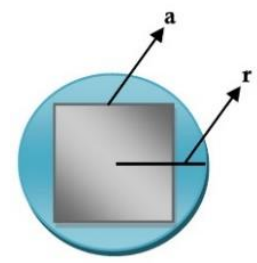

Figure 3. Cross section of the receiver tube.

Therefore, the volume of paraffin wax and water inside the receiver tube can be calculated by the following equations [26]:

$V_{p a}=a^{2} L$

$\mathrm{V}_{\mathrm{w}}=\left(\pi \mathrm{r}^{2}-\mathrm{a}^{2}\right) \mathrm{L}$

Optimization is carried out to prevent the increasing temperature of the water and paraffin wax inside the receiver tube from an identified level. On the other hand, optimization avoids the unusual increasing in tube diameter, because increasing of the tube diameter can lead to the shadiness effect on the parabolic trough concentrator that reduces the solar system efficiency.

\subsection{Thermal efficiency}

The useful energy output of the collector $\left(Q_{u}\right)$ is part of the solar energy that the working fluid receives and its temperature level increases. This amount of energy can be calculated by applying the energy balance in the volume of the working fluid, in accordance to Eq. (4) [27]:

$\mathrm{Q}_{\mathrm{u}}=\mathrm{m} \cdot \mathrm{C}_{\mathrm{P}} \cdot\left(\mathrm{T}_{\text {out }}-\mathrm{T}_{\mathrm{in}}\right)$

PTCs only use solar beam irradiation and the available solar energy $\left(Q_{s}\right)$ in the PTC aperture $\left(A_{a}\right)$ is calculated by Eq. (5) [28]:

$Q_{\mathrm{s}}=A_{\mathrm{a}} \cdot \mathrm{G}$ (6)

The thermal efficiency of the collector is defined by Eq.

$\eta_{\mathrm{th}}=\frac{\mathrm{Q}_{\mathrm{u}}}{\mathrm{Q}_{\mathrm{s}}}$

\subsection{Exergy performance}

Due to the energy analysis cannot show the internal irreversibility, on the other hand, exergy analysis generally provides a more practical and reasonable view than energy analysis [29]. In the present work, in addition to energy analysis, the PTC exergy analysis is also investigated. In thermodynamics, exergy is the maximum useful work that can be produced during a process. For solar collectors, useful exergy output $\left(E_{u}\right)$ equals the useful output energy minus the irreversibility according to Eq. (7):

$E_{u}=Q_{u}-T_{a m b} \Delta s_{g e n}$

This equation is modified into Eq. (8) [30]:

$E_{u}=Q_{u}-m \cdot C_{P} \cdot T_{a m b} \cdot \ln \left[\frac{T_{o u t}}{T_{\text {in }}}\right]$

The most acceptable model for solar exergy is introduced by ref. [31] in Eq. (9). The temperature of the sun is also approximately $5770 \mathrm{~K}$ [4]:

$E_{S}=Q_{S} \cdot\left[1-\frac{4}{3}\left(\frac{T_{\text {out }}}{T_{\text {sun }}}\right)+\frac{1}{3}\left(\frac{T_{\text {out }}}{T_{\text {sun }}}\right)^{4}\right]$

The exergy efficiency of the collector is defined as follows [32]:

$\eta_{\mathrm{ex}}=\frac{\mathrm{E}_{\mathrm{u}}}{\mathrm{E}_{\mathrm{s}}}$

Exergy efficiency indicates the quality of a process, as well as the rate of the irreversibilities. In an ideal system, this parameter tends to be 1 , but in a low-quality system, it is close to zero.

\subsection{Physical properties and simulation parameters}

The geometric parameters of the parabolic trough concentrator and the tube receiver that used in the present work are given in Table 1 . In addition to, the rest of the important parameters of the PTC system and simulation conditions such as optical efficiency, reflectivity, transmissivity and absorptivity are summarized in this table.

Table 1. Model parameters.

\begin{tabular}{cccc}
\hline Parameter & Value & Parameter & Value \\
\hline $\mathbf{f}$ & 0.8 & $\eta_{\text {opt }}$ & 0.77 \\
$\mathbf{a}_{\mathbf{c}}$ & $2.3 \mathrm{~m}$ & $\rho_{\mathrm{c}}$ & \\
$\boldsymbol{\rho}$ & 72 & $\tau_{\mathrm{g}}$ & \\
$\boldsymbol{\delta}_{\mathbf{c}}$ & $0.02 \mathrm{~m}$ & $\alpha_{\mathrm{r}}$ & \\
$\boldsymbol{\delta}_{\mathrm{GC}}$ & $0.02 \mathrm{~m}$ & $\mathrm{~h}_{\text {out }}$ & $15 \mathrm{w} / \mathrm{m}^{2} \mathrm{k}$ \\
$\mathrm{d}$ & $0.14 \mathrm{~m}$ & & \\
\hline
\end{tabular}


Solar radiation dates are derived from work [33] and properties of water and paraffin wax are presented in Table 2 using dates in works [26].

To solve the natural convection problem in the enveloped space of the PTC system, it is assumed that the flow is laminar, incompressible and transient. Thermo-physical properties such as conductivity, thermal capacity and viscosity are assumed to be constant. Also, the effect of natural convection is in accordance with Boussinesq approximation.

Table 2. Properties of water and paraffin wax [33].

\begin{tabular}{ccccc}
\hline & $\rho$ & $c_{p}$ & $h_{l}$ & $T_{\text {melt }}\left({ }^{\circ} \mathrm{C}\right)$ \\
\hline water & 998.2 & 4182 & - & - \\
Paraffin & 860 & 2500 & 188000 & 53 \\
\hline
\end{tabular}

\subsection{Boundary conditions}

In this section, the boundary conditions are presented according to some reasonable assumptions. These assumptions are similar with ref. [26].

(1) The outer surface of the concentrator is considered to be isolated to prevent heat dissipation.

(2) The lower surface of the receiver tube dealt with proportional area of the parabolic trough concentrator is exposed to reflected heat flux.

(3) For the upper surface of the receiver tube, coupled boundary condition is set.

(4) Also, the surface of the glass cover is set as coupled boundary condition.

\subsection{Numerical procedure}

Creating and meshing of the geometrical models are done by GAMBIT software. In meshing process, the shape of quad is used for the elements because this kind of elements have less numbers in comparison to other kinds of it and this decreases the calculation time. During the meshing finer grids are chosen near the walls because of the high gradients and increasing computational accuracy [34]. The generated meshes are shown in Figure 5.
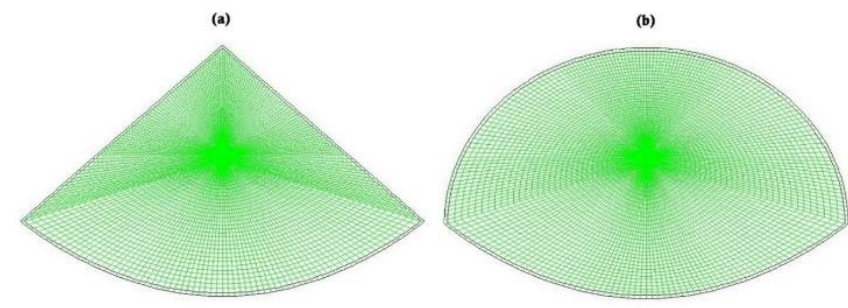

(c)

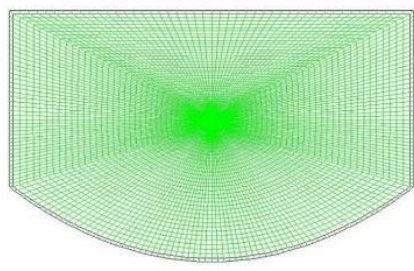

Figure5. Schematic of grid generation.

The governing equations in this work are solved using finite volume method (FVM) by Ansys Fluent V16. The transient pressure-based model with SIMPLE-Consistent method (SIMLEC) is used for simulation. The momentum and energy equations are discretized using a second-order upwind scheme and the discretization of the pressure term is with PRESTO method.

\subsection{Grid independency and time-step independency}

To make sure that the numerical results are independent of the mesh resolution, a grid independence study has been done. To investigate grid independency, in elliptical cover and time-step of 2 s, five grids with $6152,7231,8929,10444$ and 12589 cells were considered and under defined conditions, the mean temperature inside the tube, along with the phase change material for all five grids was investigated, which is presented in Figure 6. The grid independence criterion in this process was considered added temperature to the average temperature inside the tube. Comparison of the results in Figure 6 shows that the number of elements of 10444 is the most appropriate size of mesh.

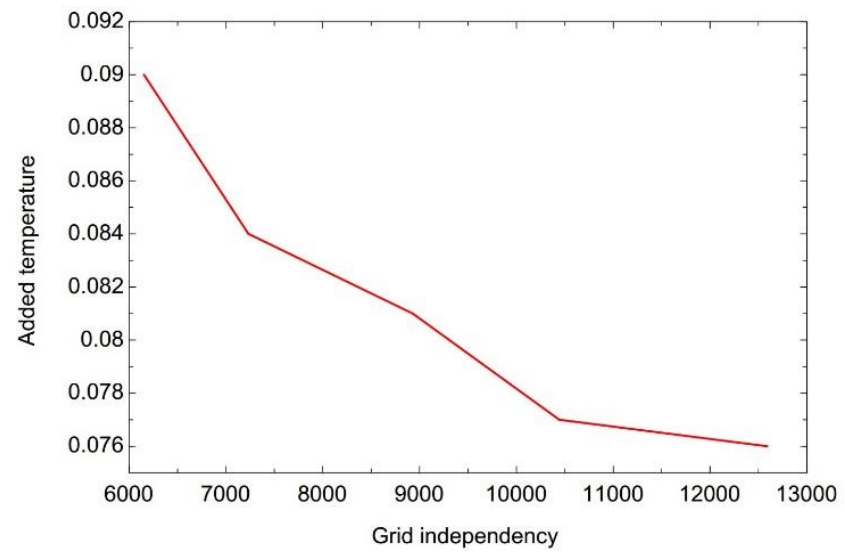

Figure 6. Grid independency study.

To investigate time-step independency, five time-steps $(1,2,3,4$ and 5s) were used with 10444 grids. As shown in Figure 7 , for the $\Delta t=2 s$, average temperature increasing inside the tube reaches to range of $1 \%$. Therefore, the time step of $2 \mathrm{~s}$ is chosen to reduce the cost of the calculations.

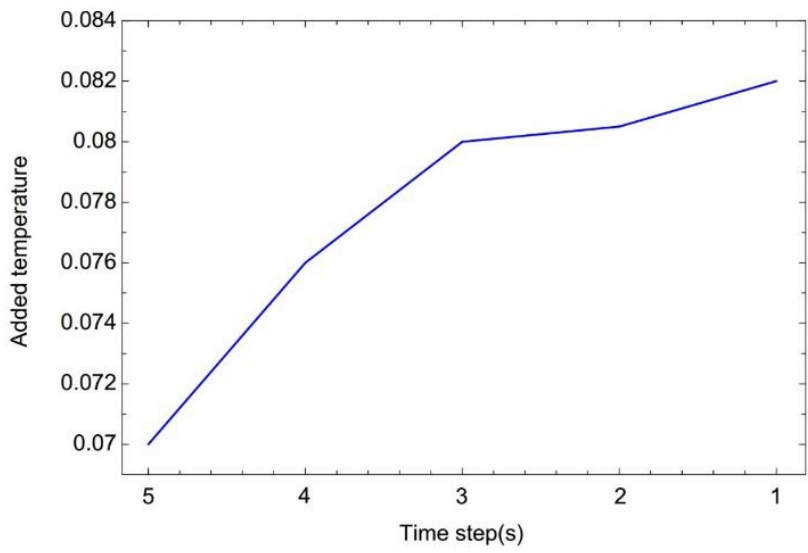

Figure 7. Time independency for model with 10444 number of meshes.

\subsection{Validation}

A numerical solution is valid when it can provide reliable prediction of the results, or at least the results have a partial difference with previous researches. The validation of the present model is performed with two comparisons. In the 
first part, thermal efficiency curve is compared with other from literature. In the other part, the values of the Nusselt number in specified Rayleigh numbers are compared between the current model and the literature results for the natural convection inside the enclosure.

In the first comparison to validate our numerical code, a case that presented in the Ref. [35] has been reproduced in this work. The PTC system with no glass cover is selected and water is used as working fluid, because there are literature data for this case. In the simulation, geometry, working conditions and materials are kept exactly identical with those in the literature. As it is seen in Figure 8, our numerical code produces the result of this reference with an acceptable accuracy.

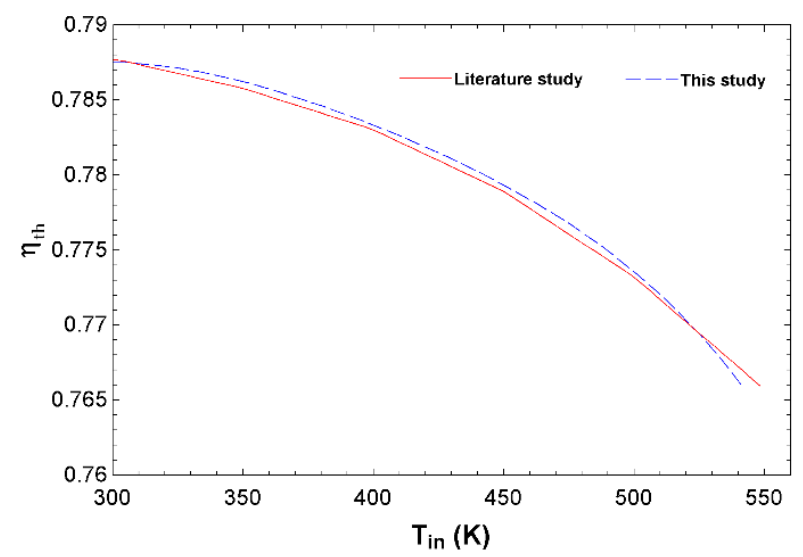

Figure 8. Comparison of our model with Ref.[35].

In the next comparison, the results in the current work have been compared with the results of two authors. Table 3 includes the comparison results between the present model and Refs.[36], [37]. These comparisons showed that our numerical code gives accurate results.

Table 3. Comparison of present work results with Refs.

\begin{tabular}{lccc}
\multicolumn{4}{c}{$[36],[37]}$. \\
\hline & $\mathbf{R a}=\mathbf{1 0}^{\mathbf{3}}$ & $\mathbf{R a}=\mathbf{1 0}^{\mathbf{4}}$ & $\mathbf{R a}=\mathbf{1 0}^{\mathbf{5}}$ \\
\hline$\overline{\mathbf{N u}}$ (Ref [36]) & 1.118 & 1.116 & 1.094 \\
$\overline{\mathbf{N u}}$ (Ref [37]) & 1.116 & 2.239 & 4.531 \\
$\overline{\mathbf{N u}}$ (Present) & 1.091 & 2.137 & 4.471 \\
\hline
\end{tabular}

\section{Results and discussions}

\subsection{Optimization}

At first based on the energy balance (Eq. (1)), optimization process has been performed to find the radius of the receiver tube in comparison to the PCM volume used inside the tube in a summer day. Summer day was considered as the basis for determining the optimum values, because peak solar irradiation occurs in summer days and energy storage level will be most. Therefore, the obtained dimensions for the receiver tube are the possible largest dimensions and for other seasons with less radiation can be used safely and there is no concern for evaporation inside it. According to Figure 3, the dimensionless coefficient $\mathrm{K}$ is defined as the ratio of the radius of the tube to the length of the square of the paraffin wax capsule:

$\mathrm{k}=\frac{\mathrm{r}}{\mathrm{a}}$

Using the properties quantity of the Table 2 in Eq. (1), the two-variables includes $\mathrm{r}$ and $a$ are derived as follows:

$$
41.26 \mathrm{r}=445.66 \mathrm{r}^{2}+92.84 \mathrm{a}^{2}
$$

Drawing this relationship between $r$ and a (Figure 8) shows that the range of the receiver tube radius is up to 0.925 (m). Also the maximum amount for the length of the paraffin wax square is $0.1014(\mathrm{~m})$ versus radius of $0.04625(\mathrm{~m})$. As seen in Figure 3, the square diameter of paraffin waxes should be smaller than the diameter of the receiver tube and the dimensionless coefficient $\mathrm{K}$ is resulted as follows:

$\mathrm{K} \geq 0.7071$

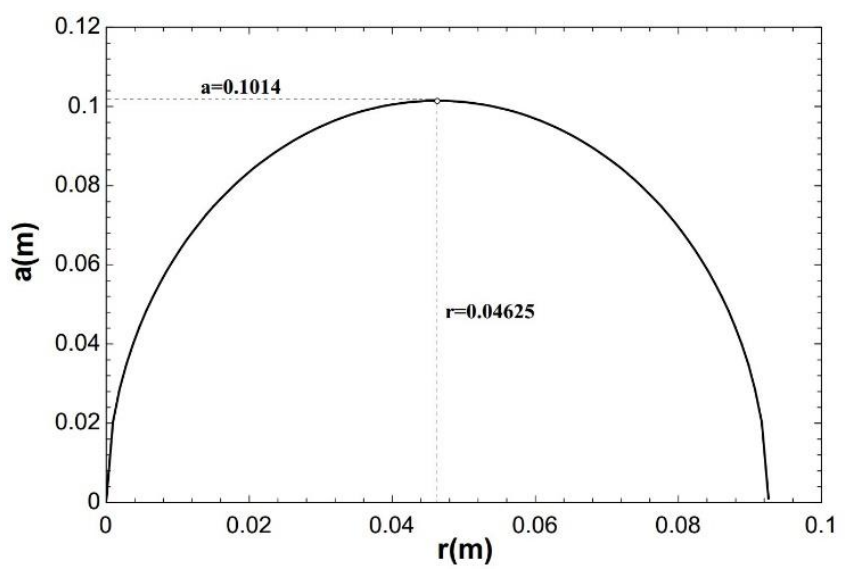

Figure 9. Variations of the square length of the paraffin wax relative to the receiver tube radius.

Variations of the coefficient $\mathrm{k}$ relative to the receiver tube radius is shown in Figure 10 and the range of values greater than 0.707 for the coefficient $\mathrm{k}$ has been specified. In order that $\mathrm{k}$ coefficient be higher than 0.707 , It is necessary, the receiver tube radius be more than $0.065 \mathrm{~m}$. According to Figures 9 and 10, the permissible range for the receiver tube radius is between $0.065 \mathrm{~m}$ and $0.0925 \mathrm{~m}$.

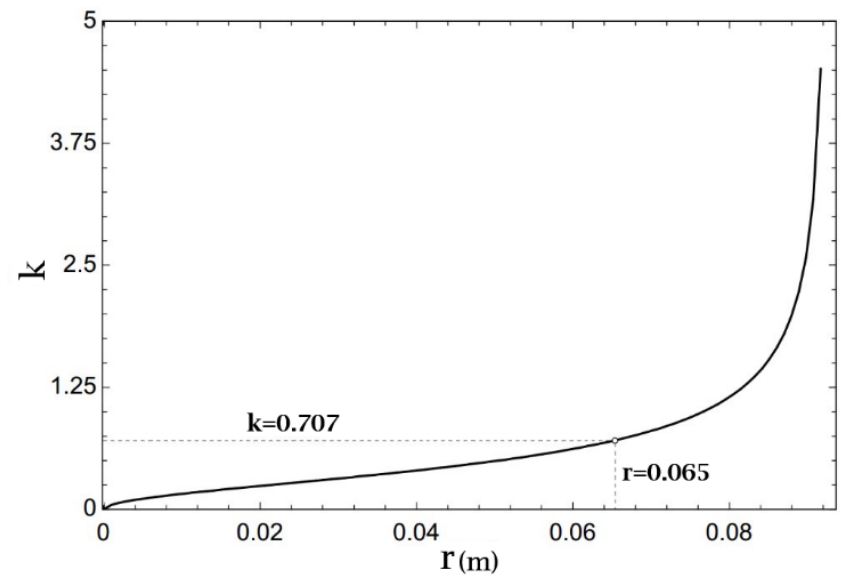

Figure 10. Variations of $k$ coefficient relative to receiver tube radius

It is important to state that large sizes of tube radius, moreover manufacturing problems and costs, face with another obstacle, the effect of the receiver shadow on the parabolic trough concentrator, so that larger radiuses by creating shadows on the concentrator have an undesirability effect on the heat absorption process. On the other hand, using proportional and smaller tubes with more paraffin wax is recommended. Considering these items in the optimization process, the minimum amount of the tube radius versus the 
maximum possible volume of paraffin wax as PCM is $\mathrm{r}=0.07$ $\mathrm{m}$ and $\mathrm{V}_{\mathrm{pa}}=7.59$ lit respectively.

\subsection{Contours}

By choosing the amount of tube radius and paraffin volume, the whole system was analyzed numerically with a transparent cover with three different geometries. Temperature distribution inside the encasement, as well as, the stream function inside it for triangular geometry on a summer day at certain hours are shown in Figures 11 and 12. One can see that, with the warming of the water and the paraffin inside the receiver tube, the air inside the encasement is heated from the heat losses on the other side of the tube by natural convection. The presence of the glass cover around the system causes the air inside it to act as a heat resistance against the heat losses and thermal dissipation from the receiver tube decreases. Temperature contours show that as more time passes from the beginning of the process, the temperature increases, because over the time, the greater amount of solar radiation absorbed by the working fluid, and consequently the pressure gradient generated in the encasement is also increased. As the temperature increases, the density decreases further, and as a result, the air circulation becomes more intense due to the thermosiphon phenomenon. Also, the stream lines show that heat losses occur through convection in the encasement. The slow heating of the encasement and intensification of the thermosiphon phenomenon also prevent over heat losses.

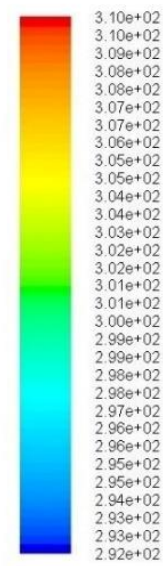

(a)
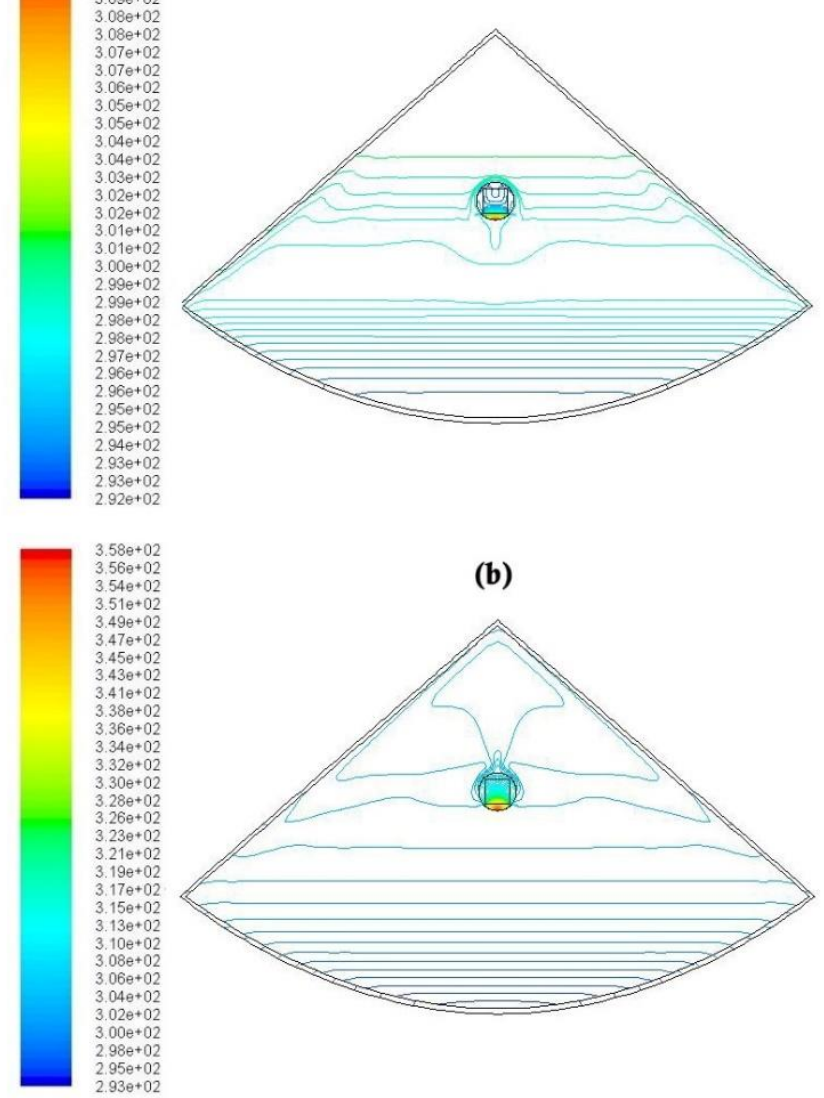

Figure 11. Temperature contours for triangular geometry: (a) Timeframe 8-9, and (b) Timeframe 15-16.

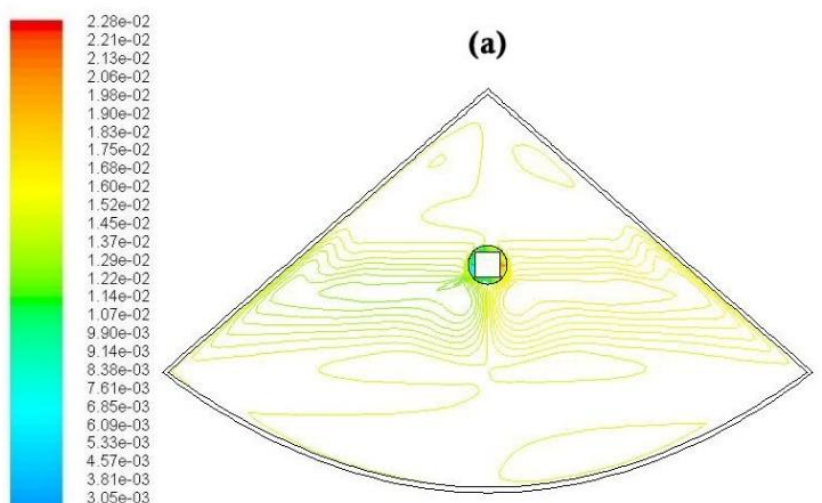

(b)

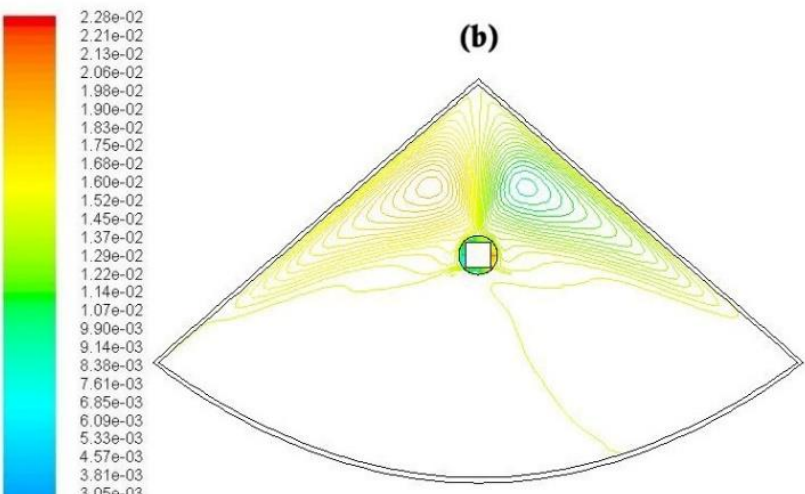

Figure 12. Stream function contours for triangular geometry: (a) Timeframe 8-9, and (b) Timeframe 15-16.

\subsection{Effects of the GC height variations on the system Performance}

To investigate effects of the height variations of the glass cover on the system performance, energy and exergy calculations were carried out on elliptical glass cover with different heights $(0.6,0.8,1$ and 1.2 meter) for a summer and a winter day. Figures 13, 14 and 15, 16 indicate the changes of the thermal and exergy efficiency of the PTC for different heights of the glass cover, respectively. It is observed whenever the geometric nature of the transparent cover is the same, energy and exergy efficiency increases sensibly with cover height decreasing. GC is transparent and can receive radiation with short wavelength, but does not pass through it out (similar to greenhouse effect). Using GC causes the air inside it to act as a heat resistance against the heat losses. It is observed that with the GC height decrease (space reduction), air inside the cover is compressed and the amount of heat dissipation is reduced and system efficiency is improved. 


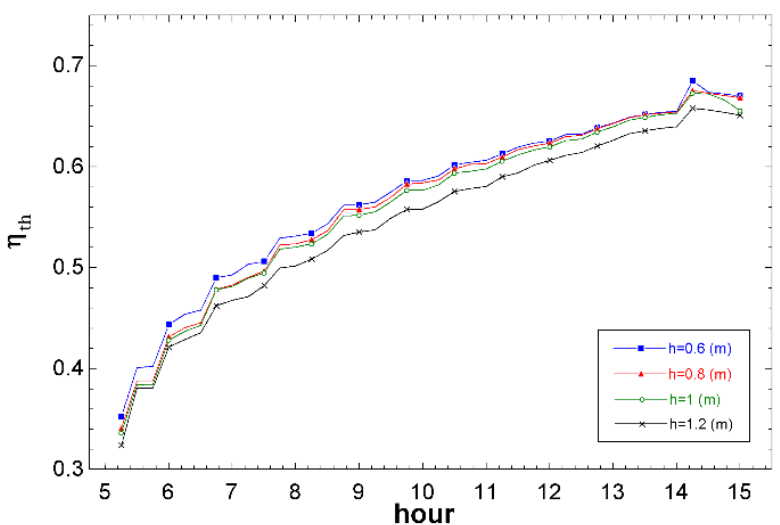

Figure 13. Variations of the thermal efficiency by changing the height of elliptical cover in a summer day.

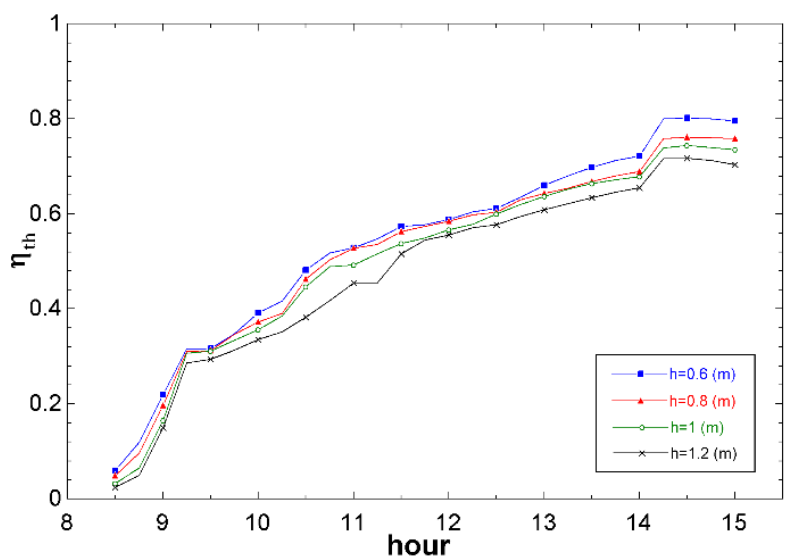

Figure 14. Variations of the thermal efficiency by changing the height of elliptical cover in a winter day.

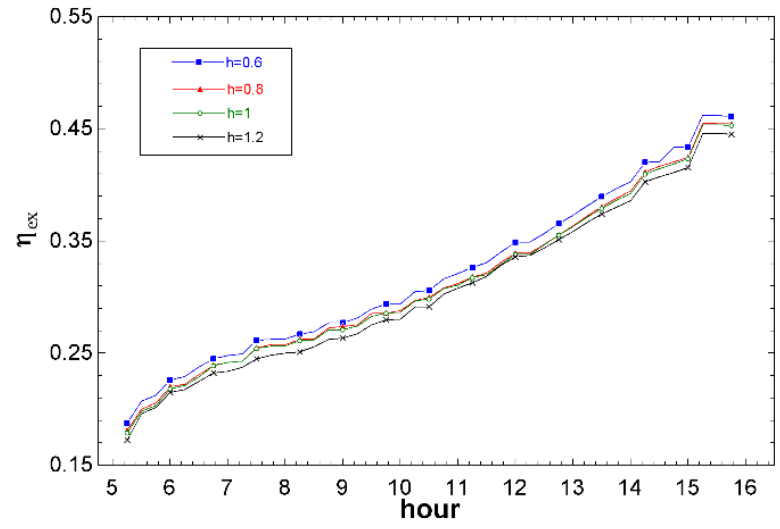

Figure 15. Variations of the exergetic efficiency by changing the height of elliptical cover in a summer day.

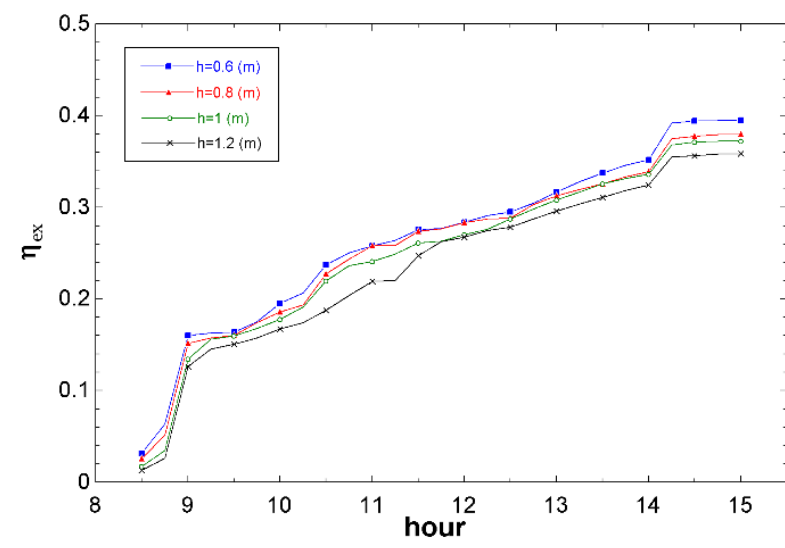

Figure 16. Variations of the exergetic efficiency by changing the height of elliptical cover in a winter day.

\subsection{Effects of the GC geometry variations on the system performance}

To evaluate and compare the performance of the PTC under the influence of transparent cover with different geometries (elliptical, triangular and rectangular cover with the same height), energy and exergy calculations were performed for a summer and a winter day. Results have been presented in figures 17, 18 and 19,20. As can be seen, system with triangularshaped cover in the same condition performs better than two other cases.

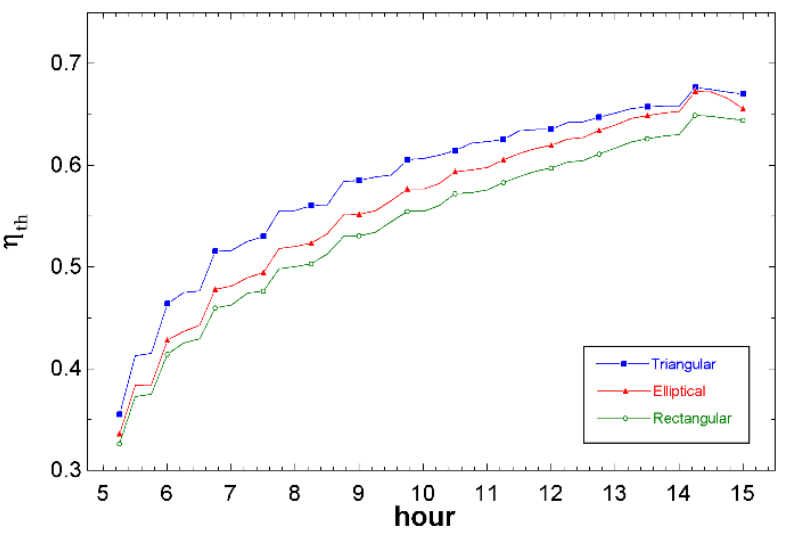

Figure 17. Thermal efficiency of the system with three different shaped cover in a summer day.

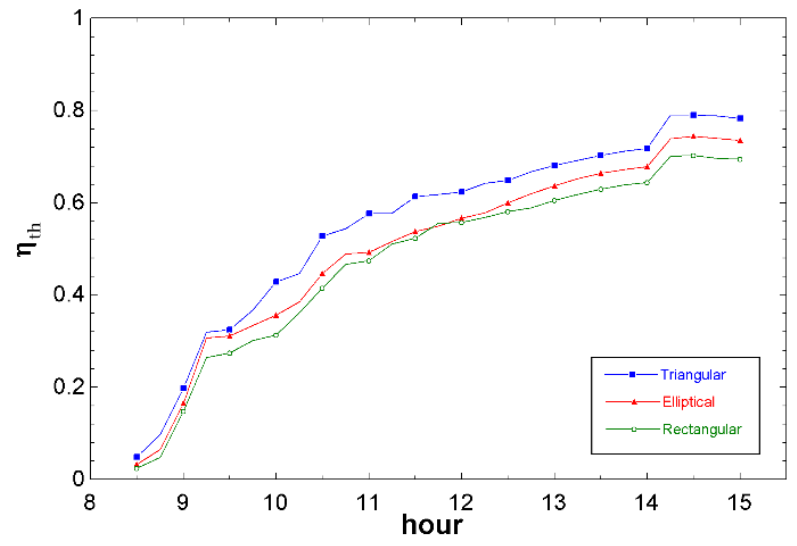

Figure 18. Thermal efficiency of the system with three different shaped cover in a winter day. 


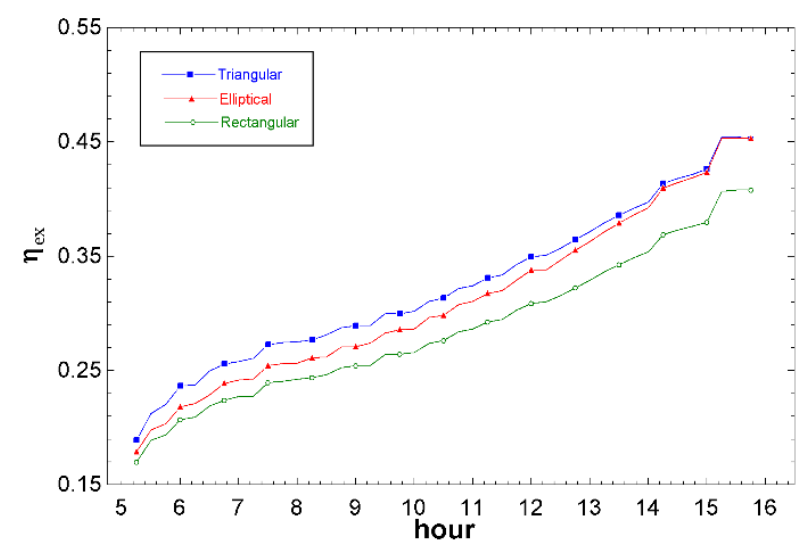

Figure 19. Exergetic efficiency of the system with three different shaped cover in a summer day.

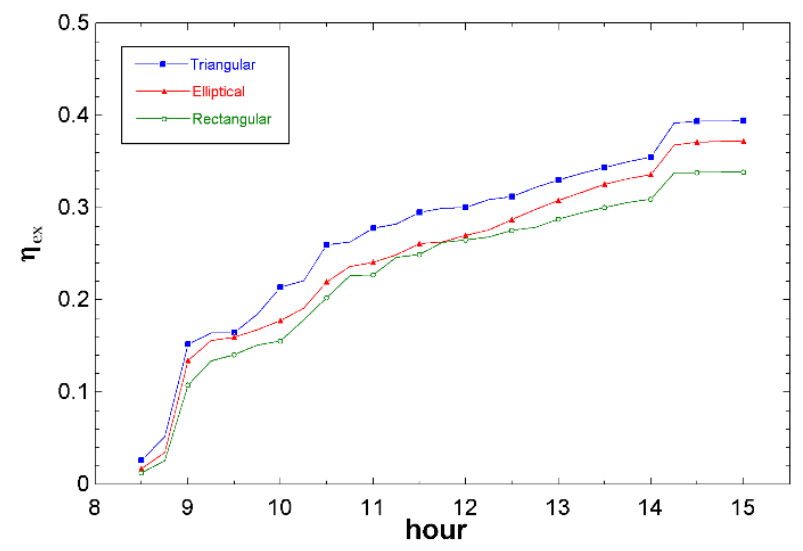

Figure 20. Exergetic efficiency of the system with three different shaped cover in a winter day.

\subsection{System performance without GC}

To compare the system performance in two cases: with GC and without GC, calculations for the current PTC system without glass cover were performed and results have been presented in Figure 21 compared to three different shaped cover. As it is seen, energy and exergy efficiency of the system are improved compared to the non-cover mode. Using GC around the system makes the air inside it to act as a heat resistance against the heat losses and thermal dissipation from the receiver and it reduces the radiation losses of the system, because the glass is transparent and receives radiations with short wavelength, but does not pass through it out.

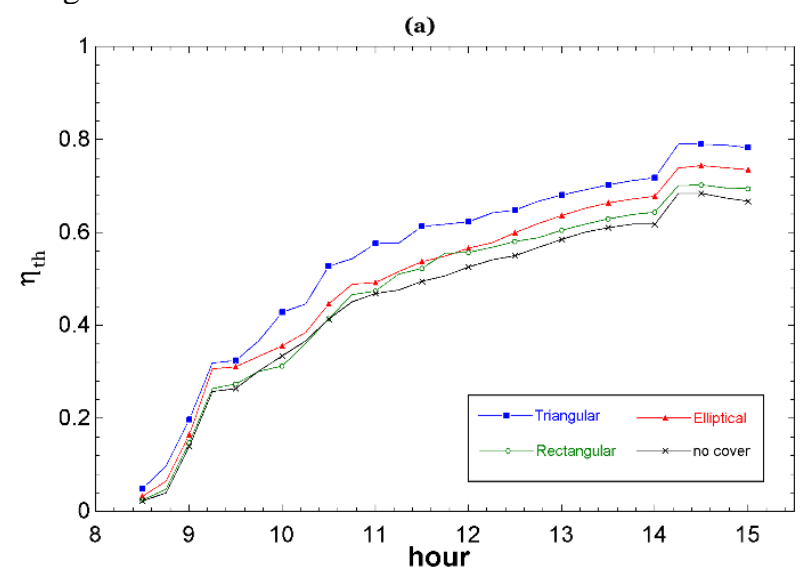

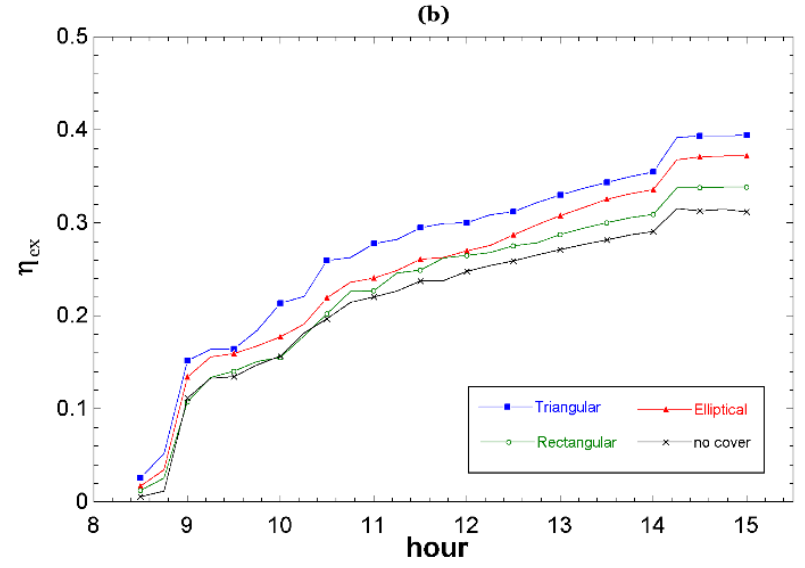

Figure 21. System efficiency without glass cover compared to three different shaped cover in a winter day: (a) thermal efficiency, (b) exergetic efficiency.

\subsection{Effects of tracking on the system performance}

The collectors are also classified as tracking and nontracking types depending on the applications. The nontracking types are fixed and usually installed and tilted at an angle equal to the latitude. The tracking collectors are again classified into single-axis and two-axis tracking. Many authors have studied sun-tracking systems. In one case, Bakos [8] conducted an experimental study to investigate the effect of tracking on the solar energy collected. In his work, a PTC system was evaluated in fixed on a $40^{\circ}$ and two-axis tracking modes, and solar radiation values were reported for these two modes as shown in Figure 22.

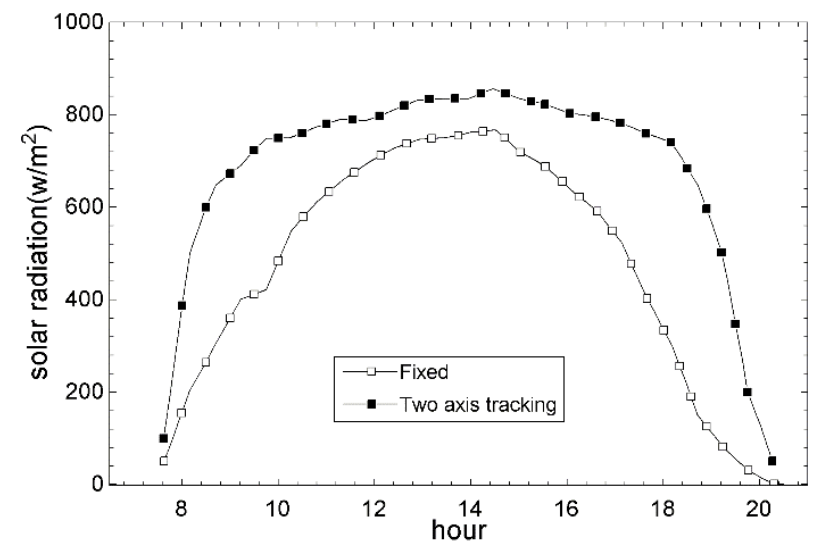

Figure 22. Solar radiation values for fixed and two-axis tracking modes.

In the present work, to survey the efficiency of the system with tracking mechanism and compare it with the fixed mode, the computations were performed for the PTC system using solar radiation data of ref. [8] and results were presented in Figure 23. As it can be seen, a reliable tracking mechanism can improve system performance. 
(a)

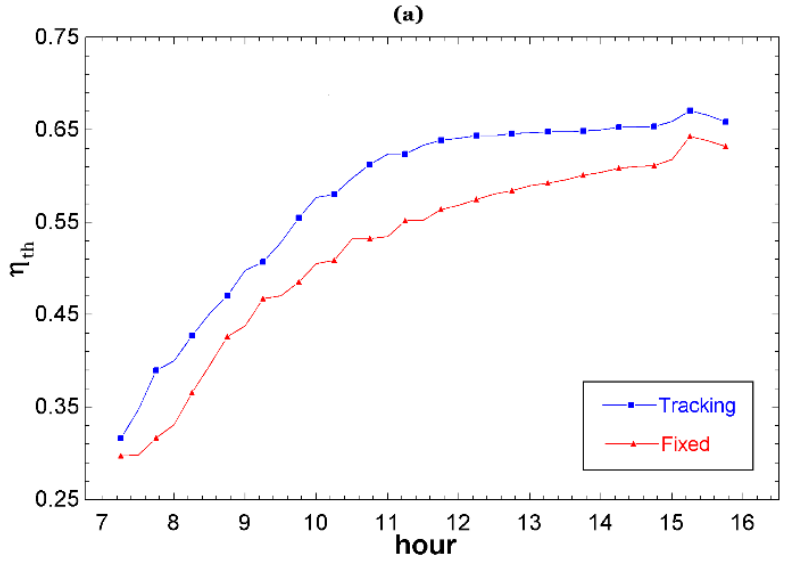

(b)

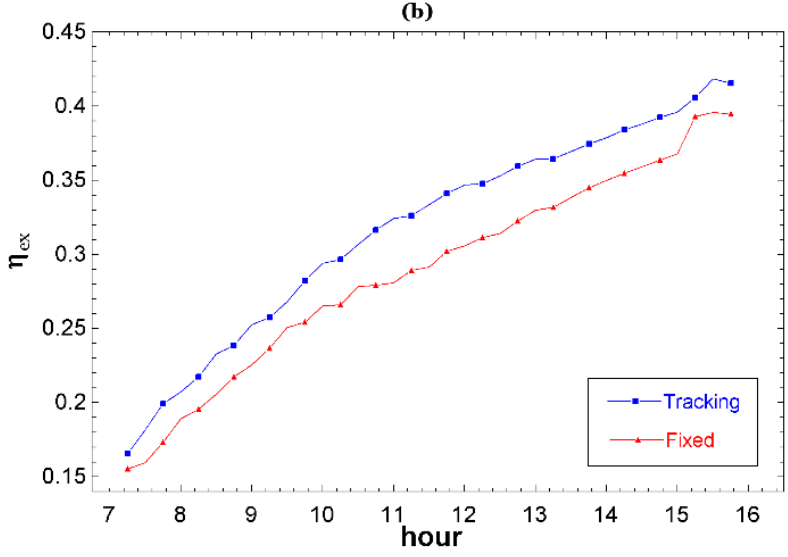

Figure 23. System efficiency with two-axis tracking compared to fixed mode: (a) thermal efficiency, (b) exergetic efficiency.

\section{Conclusions}

In the present work, we used a parabolic trough collector and receiver tube in the focal line of the concentrator. By adding a new section, glass cover, we prevented of thermal energy losses from the receiver tube, and inside it, we introduced phase change material to save energy better. An optimization process was used based on the energy balance equation to obtain a minimum tube radius against the highest volume of paraffin waxes as PCM in the warmest summer day. The results showed that by choosing the radius of the receiver tube of $7 \mathrm{~cm}$ and the volume of paraffin waxes of 59.7 lit, storage can be achieved in the least possible space. In order to better realize the phenomenon of natural convection, air flow and assessment of the system, temperature and stream function contours provided for the inside of the enveloped space with three different shaped covers. Temperature and stream function contours represent the natural convection in the enveloped space, and the heated air inside it acts as a thermal resistance against the heat dissipation from the receiver tube that leads to reduce thermal losses.

Numerical calculations were done on a summer and a winter day for PTC with three transparent cover by different geometries and for elliptical cover with heights of $0.6,0.8$, 0.1 and 1.2 meters, afterwards the effects of the geometric deformation and the change of the height of the cover on the performance of the PTC was presented as follows: (1) By evaluation the energy efficiency for the elliptical cover with different heights, it was seen that the efficiency of the system increased by decreasing the height of the transparent cover. (2) By calculating the system efficiency for transparent covers with three different geometries, the PTC with triangular cover in the same conditions had better performance than the other two (elliptical and rectangular).

To investigate the PTC in this work from the perspective of exergy, the exergy efficiency of the system for a summer and a winter day was studied and the following results were obtained: (1) Exergy efficiency has a similar procedure with thermal efficiency, and this quantity is increased by decreasing the height of the cover. (2) By examining and comparing the exergy function of the system with three different shaped cover, similar results were obtained with thermal efficiency, and the triangular cover.

\section{Nomenclature}

A $\quad$ area $\left(\mathrm{m}^{2}\right)$

$A_{\text {in,pipe }}$ surface area of the receiver tube dealt with concentrator $\left(\mathrm{m}^{2}\right)$

a length of encapsulated PCM inside the receiver tube

(m)

$a_{c} \quad$ aperture width of concentrator (m)

$C_{P} \quad$ specific heat capacity $(\mathrm{J} / \mathrm{kg} \mathrm{K})$

$d \quad$ diameter of receiver tube $(\mathrm{m})$

$E \quad$ exergy flow (W)

$f \quad$ focal length (m)

G solar irradiation $\left(\mathrm{W} / \mathrm{m}^{2}\right)$

$h_{L} \quad$ latent heat $(\mathrm{J} / \mathrm{kg})$

$m$ mass flow rate $(\mathrm{kg} / \mathrm{s})$

$\mathrm{Nu} \quad$ mean Nusselt number

$\mathrm{Nu}$ mean Nusselt number

$Q \quad$ heat flux (w)

$\mathrm{Ra} \quad$ Rayleigh number

$r \quad$ radius of receiver tube $(\mathrm{m})$

$T$ temperature (K)

$V \quad$ volume $\left(\mathrm{m}^{3}\right)$

\section{Greek symbols}

$\Delta s \quad$ entropy increase $(\mathrm{J} / \mathrm{kg})$

$\delta \quad$ thickness (m)

$\varphi \quad$ rim angle

$\eta \quad$ efficiency

$\rho \quad$ density $\left(\mathrm{kg} / \mathrm{m}^{3}\right)$

$\eta_{\text {opt }} \quad$ optical efficiency

$\tau_{g} \quad$ transmissivity of glass cover

$\rho_{c} \quad$ reflectivity of concentrator

$\alpha_{r} \quad$ absorptivity of receiver tube

\section{Subscripts and superscripts}

a aperture

amb ambient

c concentrator

ex exergetic

GC glass cover

$i$ initial

in inlet

melt melting point

out outlet

pa paraffin

$S \quad$ solar

sun sun

th thermal

$u$ useful

w water 


$\begin{array}{ll}\text { Abbreviations } \\ \text { HTF } & \text { heat transfer fluid } \\ \text { PCM } & \text { phase change material } \\ \text { PTC } & \text { parabolic trough collector }\end{array}$

References:

[1] O. Kizilkan, A. Kabul, and I. Dincer, "Development and performance assessment of a parabolic trough solar collector-based integrated system for an ice-cream factory," Energy, vol. 100, pp. 167-176, 2016.

[2] W. A. Hermann, "Quantifying global exergy resources," Energy, vol. 31, no. 12, pp. 1685-1702, 2006.

[3] E. Bellos, D. Korres, C. Tzivanidis, and K. A. Antonopoulos, "Design, simulation and optimization of a compound parabolic collector," Sustain. Energy Technol. Assessments, vol. 16, pp. 53-63, 2016.

[4] S. A. Kalogirou, Solar thermal collectors and applications, vol. 30, no. 3. 2004.

[5] L. Zhou, Y. Li, E. Hu, J. Qin, and Y. Yang, "Comparison in net solar efficiency between the use of concentrating and non-concentrating solar collectors in solar aided power generation systems," Appl. Therm. Eng., vol. 75, pp. 685-691, 2015.

[6] Y. Wang, J. Xu, Q. Liu, Y. Chen, and H. Liu, "Performance analysis of a parabolic trough solar collector using A12O3/synthetic oil nanofluid," Appl. Therm. Eng., vol. 107, pp. 469-478, 2016.

[7] J. Chen, L. Yang, Z. Zhang, J. Wei, and J. Yang, "Optimization of a uniform solar concentrator with absorbers of different shapes," Sol. Energy, vol. 158, no. September, pp. 396-406, 2017.

[8] G. C. Bakos, "Design and construction of a twoaxis Sun tracking system for parabolic trough collector (PTC) efficiency improvement," Renew. Energy, vol. 31, no. 15, pp. 2411-2421, 2006.

[9] A. Valan Arasu and T. Sornakumar, "Design, manufacture and testing of fiberglass reinforced parabola trough for parabolic trough solar collectors," Sol. Energy, vol. 81, no. 10, pp. 1273 1279, 2007.

[10] P. Mohammad Zadeh, T. Sokhansefat, A. B Kasaeian, F. Kowsary, and A. Akbarzadeh, "Hybrid optimization algorithm for thermal analysis in a solar parabolic trough collector based on nanofluid," Energy, vol. 82, pp. 857-864, 2015.

[11] J. Paetzold, S. Cochard, A. Vassallo, and D. F. Fletcher, "Wind engineering analysis of parabolic trough solar collectors: The effects of varying the trough depth," J. Wind Eng. Ind. Aerodyn., vol. 135, pp. 118-128, 2014.

[12] J. J. Serrano-Aguilera, L. Valenzuela, and J. Fernández-Reche, "Inverse Monte Carlo RayTracing method (IMCRT) applied to line-focus reflectors," Sol. Energy, vol. 124, pp. 184-197, 2016.

[13] F. Wang, J. Tan, L. Ma, and C. Wang, "Effects of glass cover on heat flux distribution for tube receiver with parabolic trough collector system," Energy Convers. Manag., vol. 90, pp. 47-52, 2015.
[14] B. Zou, J. Dong, Y. Yao, and Y. Jiang, "An experimental investigation on a small-sized parabolic trough solar collector for water heating in cold areas," Appl. Energy, vol. 163, pp. 396-407, 2016.

[15] M. Potenza, M. Milanese, G. Colangelo, and A. de Risi, "Experimental investigation of transparent parabolic trough collector based on gas-phase nanofluid," Appl. Energy, vol. 203, pp. 560-570, 2017.

[16] A. A. Hachicha, I. Rodríguez, J. Castro, and A. Oliva, "Numerical simulation of wind flow around a parabolic trough solar collector," Appl. Energy, vol. 107, pp. 426-437, 2013.

[17] B. Lamrani, A. Khouya, B. Zeghmati, and A. Draoui, "Mathematical modeling and numerical simulation of a parabolic trough collector: A case study in thermal engineering," Therm. Sci. Eng. Prog., vol. 8, no. July, pp. 47-54, 2018.

[18] S. K. Tyagi, S. Wang, M. K. Singhal, S. C. Kaushik, and S. R. Park, "Exergy analysis and parametric study of concentrating type solar collectors," Int. J. Therm. Sci., vol. 46, no. 12, pp. 1304-1310, 2007.

[19] A. Bejan, D. W. Kearney, and F. Kreith, "Second Law Analysis and Synthesis of Solar Collector Systems," J. Sol. Energy Eng., vol. 103, no. 1, p. 23, 2010 .

[20] A. Allouhi, M. Benzakour Amine, R. Saidur, T. Kousksou, and A. Jamil, "Energy and exergy analyses of a parabolic trough collector operated with nanofluids for medium and high temperature applications," Energy Convers. Manag., vol. 155, no. August 2017, pp. 201-217, 2018.

[21] M. Chafie, M. F. Ben Aissa, and A. Guizani, "Energetic end exergetic performance of a parabolic trough collector receiver: An experimental study," J. Clean. Prod., vol. 171, pp. 285-296, 2018.

[22] A. Mwesigye, İ. H. Y1lmaz, and J. P. Meyer, "Numerical analysis of the thermal and thermodynamic performance of a parabolic trough solar collector using SWCNTs-Therminol@VP-1 nanofluid," Renew. Energy, vol. 119, pp. 844-862, 2018.

[23] P. V. Bhale, M. K. Rathod, and L. Sahoo, "Thermal Analysis of a Solar Concentrating System Integrated with Sensible and Latent Heat Storage," Energy Procedia, vol. 75, pp. 2157-2162, 2015.

[24] J. Guo and X. Huai, "Multi-parameter optimization design of parabolic trough solar receiver," Appl. Therm. Eng., vol. 98, pp. 73-79, 2016.

[25] C. Zhang, G. Xu, Y. Quan, H. Li, and G. Song, "Optical sensitivity analysis of geometrical deformation on the parabolic trough solar collector with Monte Carlo Ray-Trace method," Appl. Therm. Eng., vol. 109, pp. 130-137, 2016.

B. M. Ziapour and A. Hashtroudi, "Performance study of an enhanced solar greenhouse combined with the phase change material using genetic algorithm optimization method," Appl. Therm. Eng., vol. 110, pp. 253-264, 2017. 
[27] E. Bellos, C. Tzivanidis, I. Daniil, and K. A. Antonopoulos, "The impact of internal longitudinal fins in parabolic trough collectors operating with gases," Energy Convers. Manag., vol. 135, pp. 3554, 2017.

[28] C. Tzivanidis, E. Bellos, D. Korres, K. A. Antonopoulos, and G. Mitsopoulos, "Thermal and optical efficiency investigation of a parabolic trough collector," Case Stud. Therm. Eng., vol. 6, pp. 226-237, 2015.

[29] J. Yazdanpanahi, F. Sarhaddi, and M. Mahdavi Adeli, "Experimental investigation of exergy efficiency of a solar photovoltaic thermal (PVT) water collector based on exergy losses," Sol. Energy, vol. 118, pp. 197-208, 2015.

[30] E. Bellos, C. Tzivanidis, K. A. Antonopoulos, and G. Gkinis, "Thermal enhancement of solar parabolic trough collectors by using nanofluids and converging-diverging absorber tube," Renew. Energy, vol. 94, pp. 213-222, 2016.

[31] N. Enteria, E. Gr, H. S. View, T. C. View, and N. Enteria, Solar Energy Sciences and Engineering Applications, no. January 2013. CRC Press, 2013.

[32] E. Bellos, C. Tzivanidis, K. A. Antonopoulos, and
I. Daniil, "The use of gas working fluids in parabolic trough collectors - An energetic and exergetic analysis," Appl. Therm. Eng., vol. 109, pp. 1-14, 2016.

[33] M. Grigiante, F. Mottes, D. Zardi, and M. de Franceschi, "Experimental solar radiation measurements and their effectiveness in setting up a real-sky irradiance model," Renew. Energy, vol. 36, no. 1, pp. 1-8, 2011.

[34] H. Eslamnezhad and A. B. Rahimi, "Enhance heat transfer for phase-change materials in triplex tube heat exchanger with selected arrangements of fins," Appl. Therm. Eng., vol. 113, pp. 813-821, 2017.

[35] E. Bellos, C. Tzivanidis, and K. A. Antonopoulos, "A detailed working fluid investigation for solar parabolic trough collectors," Appl. Therm. Eng., vol. 114, pp. 374-386, 2017.

[36] G. D. E. V. Davis and I. P. Jones, "Natural convection in," Int. J., vol. 3, no. July 1982, pp. 227-248, 1983.

[37] R. D. C. Oliveski, M. H. Macagnan, and J. B. Copetti, "Entropy generation and natural convection in rectangular cavities," Appl. Therm. Eng., vol. 29, no. 8-9, pp. 1417-1425, 2009. 